\title{
Investigations of Decoupled Trigonometric Saturated and Fuzzy Logic Techniques for the Automatic Frequency Control of Islanded Microgrid
}

\author{
Mohammed Alshehri and Sreerama Kumar R.
}

\begin{abstract}
This paper involves the investigation of new techniques for the automatic load frequency control of islanded Microgrids. Microgrids are being established as a part of smart grid environment. In modern power systems, smart grid represents the solution for many of traditional power system problems such as frequency fluctuations. Frequency fluctuations have negative consequences in terms of electrical equipment life, production cost and production losses relative to costumers and electricity producers. So, the frequency of power system must be kept in acceptable range. In order to operate a power system with fixed frequency, it is necessary to always maintain a balance between the generation and the consumption of active power. The frequency droop control methods are widely used to control active power and frequency of the parallel synchronous generators in the traditional power grid. At present, this method has also been applied to the control of parallel inverters to share the load demand in proportion to their ratings. In order to improve the frequency control of traditional droop control technique applied in islanded microgrid. It is proposed to investigate the Decoupled Trigonometric Saturated (DTS) and fuzzy droop control techniques on islanded microgrids which uses meshed parallel inverter systems. To verify the performance of the proposed ALFC based on Decupled trigonometric saturated controller, fuzzy PI controller the MATLAB/SIMULINK environment is used.
\end{abstract}

Index Terms - Active Power frequency controller, Decoupled trigonometric saturated droop controller, Fuzzy PI controller, Islanded Microgrid.

\section{INTRODUCTION}

Microgrids (MG) are discrete electric networks consisting of small scale power sources, distribution network, load, storage element, MG controller and power conversion system (PCS)[1]. Microgrid power sources include both renewable and traditional sources such as photovoltaic (PV) units, wind turbines, small hydro and combined heat and power (CHP) stations [2]. Microgrid system can have, Alternative current (AC) and Direct Current (DC) power sources. So, the MG to feeds AC load needs to convert from DC power source to AC by one or more of inverters and control them to work coherently with same voltage, frequency, phase sequence, and in phase with each other [3].

Several approaches and configurations are available to deliver power to the load, first by connecting the distributing generation (DG) unit in parallel to feed one bus that connected to the load side. This structure called "bus

Submitted on May 10, 2021.

Published on June 30, 2021.

Mohammed Ali Alshehri, King Abdulaziz University, Saudi Arabia

(e-mail: moh.ali0915@gmail.com) structure" as shown in Fig. 1 (a). The other structure is "meshed structure" where the DG unit and the load can be connected in any node of microgrid as shown in Fig. 1 (b). In the bus type, inverters are connected to a common ac bus. But in a meshed parallel system inverters and loads can be connected to any node [5]. In this research a meshed parallel system consisting of four DGs supplying to the load through high inductive network is chosen for investigation.

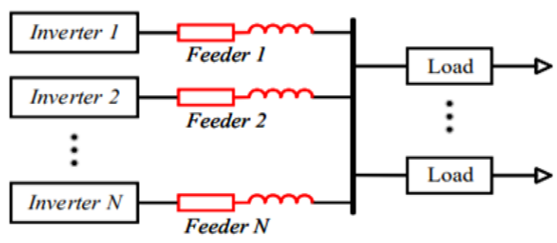

(a)

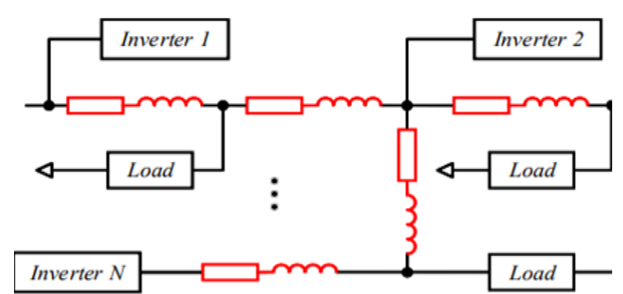

(b)

Fig. 1. Different structure of a parallel inverters system. (a) Common bus structure. (b) Meshed structure.

In the Islanded microgrid, the sources need to be controlled to provide constant frequency and voltage because contrary to the grid-connected Microgrid that its voltage and frequency controlled by the main grid. The constant frequency can be achieved by maintain a balance between the power generation and the load demand irrespective of any system disturbances or complete loss of generation, transmission distribution and the sudden change in consumer loads. To control the frequency and active power, many techniques have been developed [8].

The droop control method is widely used to control active power and frequency control [9]. This method uses traditional droop control method to simulate the operation characteristics of the parallel synchronous generators in the traditional power grid, using the frequency of the generator terminal voltage. At present, this method is also applied to the control of parallel inverters to share the load demand without communication infrastructure. 
Recent studies have used several methods to control the active power and frequency in Microgrid [8], such as droop control, Emulation of Synchronous Generator Control, Dynamic Demand Control, Observer-Based Load Frequency Control (OBLFC), and Fuzzy logic based intelligent control.

Recently, finding a proper balance between power sharing and voltage regulation, making a better performance for MG's dynamics, and transferring between islanded mode to grid connected mode, is one of the major concerns for the stable operation of MGs [10]. Lu has developed a new scheme "distributed secondary cooperative control' to compromise DGs in islanded MGs by using algorithm based on a finite-time frequency regulation strategy and distributed active power regulator based on consensus, to provide active power sharing and recover DGs' frequencies to the reference value within a relatively small time [13]. Nearest-neighbor communication protocol has been employed [14] by J.W. Simpson to present secondary frequency and voltage control to perform secondary control actions. This distributed control approach gives more flexibility.

To recover frequency of DG to a rated value without affecting its reactive power output, changeable frequency reference [15] has been proposed by Chunxia, Zhanqiang Zhang, Dong Yue and Hanxiao Gao.

Liang Haifeng has presented the "anti-S" droop control strategy based on replacing the droop line with a curve to improve the frequency stability of operating multiple inverters in parallel in case of islanded mode [16]. However, this method does not give a solution for frequency recovery. $\mathrm{Li}$ Yanqing has achieved frequency recovery in islanded mode by adjusting the value of power corresponding to frequency in the droop curve [17], [18]. Fuzzy PI control is proposed by Zhenhai Sun, Shuhuai An, Zhen Wei, Faxiang Qiu, and Kelun Zhong [19] to adjust the scale factor that affects the frequency adjustment speed to prevent the frequency deviation.

L. Wu at el. have introduced a coordinated control strategy to coordinate the requirement of active power and reactive power regulation. Higher order sliding mode observer based integral higher order sliding mode controller has been proposed for enhancing the finite time convergence of frequency and area control error under disturbances with chattering free control signal [21]. This method has reduced the frequency deviation under random load disturbances.

An improved droop control method has been presented in [22] to provide power decoupling and reactive power sharing for low voltage microgrid. The introduced method utilizes the virtual power source (VPS) and composite virtual impedance, which is represented by a negative resistance and a negative inductance. Allal El Moubarek Bouzida, Pierre Sicarda, Hicham Chaouib, Ahmed Cheritia, Manuela Sechilariuc, and Josep M. Guerrerod [10] have proposed a novel droop control based on Decoupled Trigonometric Saturated (DTS) controller for stable power sharing applied to meshed parallel inverter systems in islanded microgrids. The novel DTS control scheme is introduced to increase the power-sharing accuracy with a better stability and to provide a dynamic decoupling of active and reactive power in the presence of different impedances.

In this paper, it is proposed to investigate the effectiveness of the Decoupled Trigonometric Saturated (DTS) and the fuzzy droop control techniques in the load-frequency control of islanded microgrids using meshed parallel inverter systems.

The rest of paper is follows as Section II. discusses the isolated microgrid configuration and system modeling aspects. In Section III. the conventional droop ALFC control method is discussed. In Section IV and section V involves with the DTS controller and Fuzzy logic controller. System data and simulation results is represented in Section VI. Finally, Section VII. concludes the paper.

\section{ISLANDED MICROGRID CONFIGURATION AND SYSTEM MODELING ASPECT}

Microgrids [4] are required to be able to work in Isolated mode independently and microgrid controller function is to control the frequency and voltage. The other operating mode is grid-connected mode where the microgrid operate synchronously with the main grid and the microgrid controller function is to control the active and reactive power injected into the grid or consumed by the microgrid. In this paper, the performance of various types of microgrid controllers in the islanded mode of operation investigated as shown in Fig. 2.

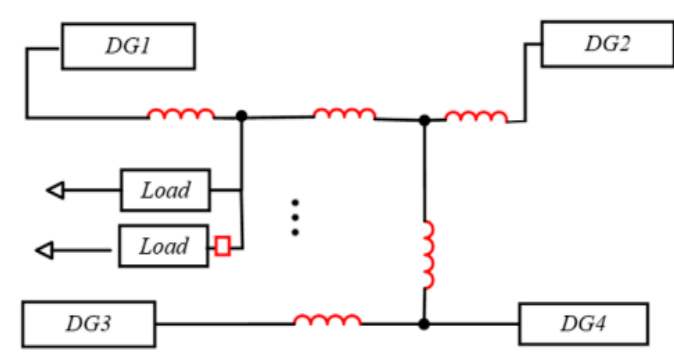

Fig. 2. Block diagram of a microgrid.

- DC Source:

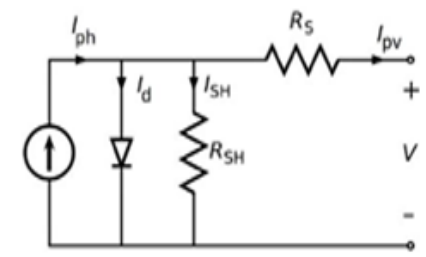

(a)

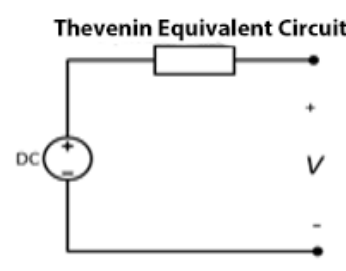

(b)
Fig. 3. (a) PV Energy Source Model(b) Wind Energy Source Model.

Photovoltaic (PV) units and wind turbines stations are the common sources used for Microgrid and usually these are Direct Current (DC) sources. Thus, in this research we uses simple DC source as shown in Fig. 3. to simulate the role of PV or wind turbine at steady state.

- Inverter:

An inverter is a device that gives an AC-output from a DC input by using bridge circuit of an IGBTs (Insulated-Gate Bipolar Transistor) [8] as shown in Fig. 4. IGBT needs to be controlled by a Pulse Width Modulated (PWM) signal. The three phase output of the inverter is connected to the network. The output voltage and current are always measured and compared with the reference signal by control circuit designed to control the voltage, frequency, and the power at various desired points in the microgrid. 


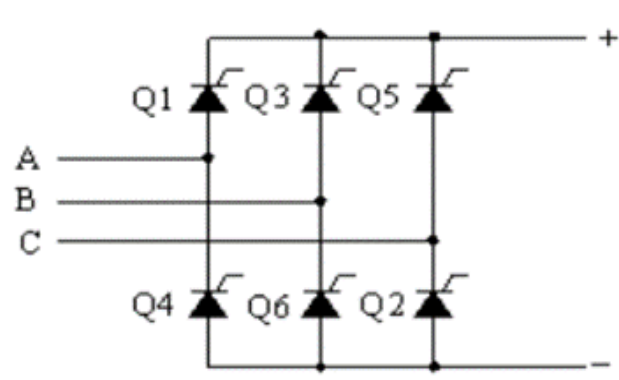

Fig. 4. Three phase inverter structure.

- Filter:

The output filter connected to the inverter's output is used to reduce harmonics that is caused by the switching of semiconductor devices. There are various types of filters. The simplest one is the inductor filter [27]. But various combinations of inductor and capacitors like LC or LCL can be used. Fig. 5. shows a typical configuration of an LCL filter.

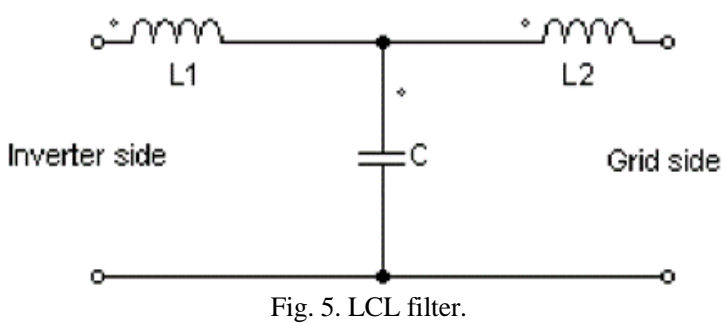

- Microgrid Controller

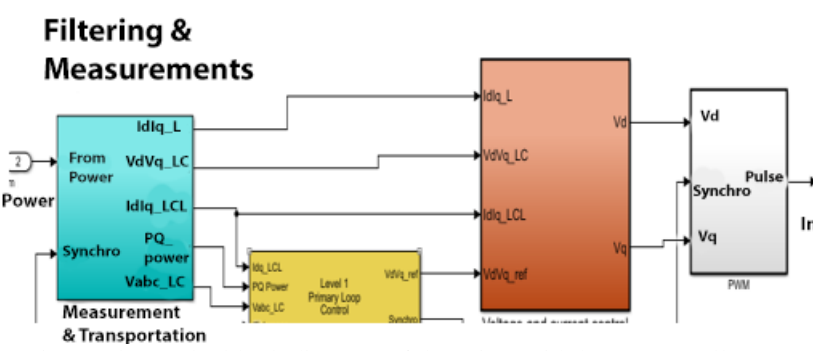

Fig. 6. Shows the block diagram of the microgrid droop controller.

As shown in the Fig.6. , cascaded control loops are used to stabilize the output voltage and current of the inverter [13].

The first block is filtering and measurements of signals. The output of this block is the current and voltage of the inverter and LCL filter with DQ coordination. Another output of the filtering and measurement block is the active and reactive power, delivered to the common bus by the inverter. The second block is the primary control loop responsible for providing the voltage reference to the outer control. Finally, the third block contains the voltage and current control loops. The primary function of the voltage outer loop is to determine the reference value of the inner current loop. The primary function of the current inner loop is to accomplish accurate tracking of a current. The pulse width modulator then generates the necessary pluses for the inverter gate.

\section{Conventional Automatic LAOD FreQuency CONTROL}

In the conventional droop control, the output impedance of inverter is treated as purely inductive because it has a high ratio of inductance to resistance for filter and line. The equivalent circuit of two inverters connected in parallel is shown in Fig. 7.

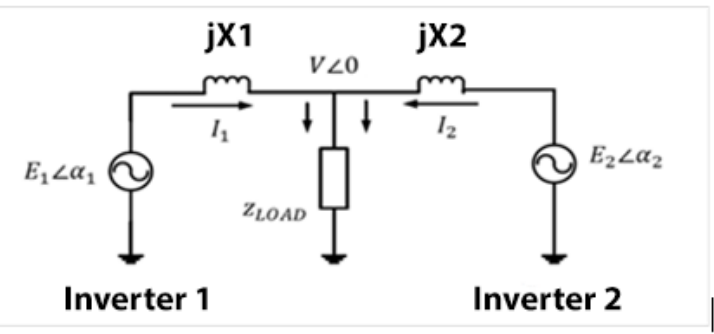

Fig. 7. Equivalent model of two inverters connected in parallel.

In an inductive system, the active and reactive power drawn to a bus from each inverter can be expressed as follows:

$$
\begin{aligned}
& \mathrm{P}=(E V \sin \alpha) / \mathrm{x} \\
& \mathrm{Q}=\left(\mathrm{EV} \cos \alpha-\mathrm{V}^{\wedge} 2\right) / \mathrm{x}
\end{aligned}
$$

where $\mathrm{E}$ and $\mathrm{V}$ are the inverter output voltage and the bus voltage respectively, $\alpha$ is the power angle that represent the phase shift between $\mathrm{E}$ and $\mathrm{V}$, and $\mathrm{x}$ is the output reactance of the inverter. Based on equations (1) and (2) and small power angle $\alpha(\sin \alpha \approx \alpha$ and $\cos \alpha=1)$, the active power injected to the bus is directly influenced by the power angle $\alpha$. But the reactive power is dependent on the difference between $E$ and $\mathrm{V}(\mathrm{V}(\mathrm{E}-\mathrm{V}))$. Fig. 8 shows the block diagram of the conventional droop control. Where Fig. 9 shows droop line of P- $\omega$ and Q-E.

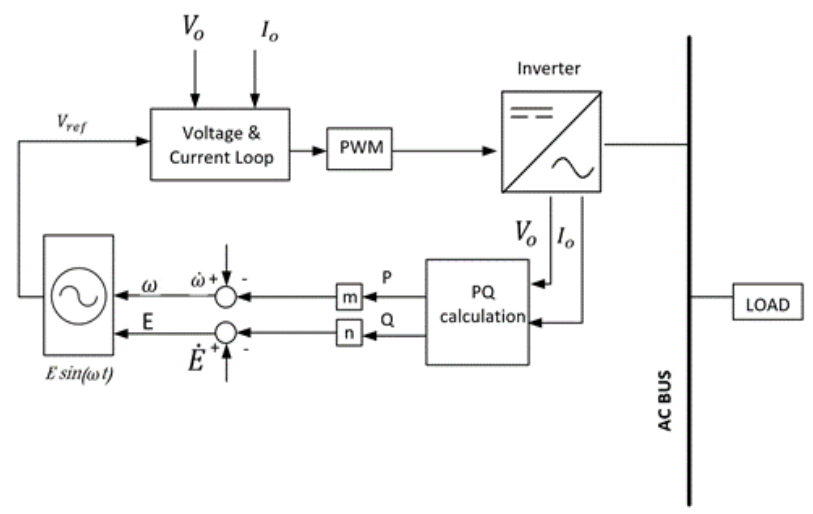

Fig. 8. Block diagram of conventional droop control.
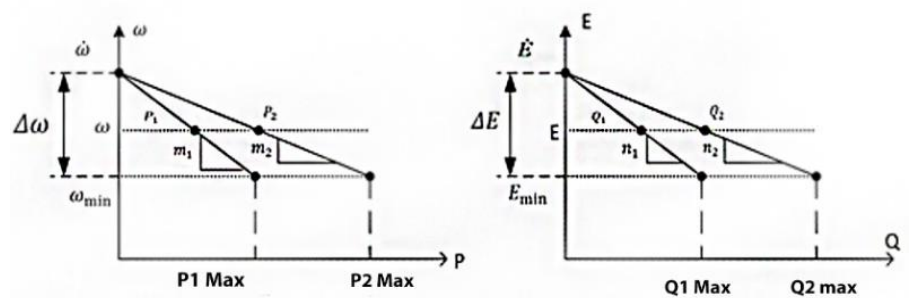

Fig. 9. a) P- $\omega$ droop b) Q-E droop.

From Fig. 9, the equations of the droop line of $\mathrm{P}-\omega$ and $\mathrm{Q}$ - E can be written as follows:

$$
\omega \_k=\omega^{\cdot}-\mathrm{m} \_\mathrm{k} p \_\mathrm{k}
$$




$$
\mathrm{E} \_\mathrm{k}=\mathrm{E} \cdot-\mathrm{n} \_\mathrm{k} Q \mathrm{Q}
$$

where $\mathrm{p} \_\mathrm{k}, \mathrm{Q} \_\mathrm{k}, \mathrm{m} \_\mathrm{k}$, and $\mathrm{n} \_\mathrm{k}$ are the active power, reactive power, frequency droop coefficient, and voltage droop coefficient of the Kth inverter, respectively. The rated frequency is written as $\omega^{\circ}$, and $\mathrm{E}^{*}$ is the rate voltage. From (3) and (4), the frequency and voltage droop coefficient can be written as:

$$
\begin{aligned}
& \mathrm{m} \_\mathrm{k}_{-}=\Delta \mathrm{w} / \mathrm{P} \_\mathrm{kmax} \\
& \mathrm{n} \_\mathrm{k}=\Delta \mathrm{E} / \mathrm{Q} \_\mathrm{kmax}
\end{aligned}
$$

where $\Delta \omega$ and $\Delta \mathrm{E}$ are the maximum acceptable deviation

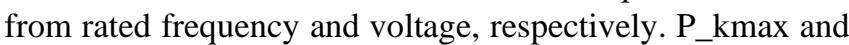
Q_kmax are the peak active and reactive power supplied by the system respectively. [6], [7], [16].

\section{DeCOUPLED TRIGONOMETRIC SATURATED BASED LOAD FREQUENCY CONTROL}

Fig. 10. shows the power flow from the inverter through a transmission line to a load. In this figure, E represents the terminal voltage of the inverter, $\mathrm{V}$ is the bus terminal voltage, $\alpha$ is the phase shift between the terminal voltage of the inverter $\mathrm{E}$ and bus $\mathrm{V}, \mathrm{P}+\mathrm{jQ}$ is the load demand, and $\mathrm{Z}$ is the transmission line impedance.

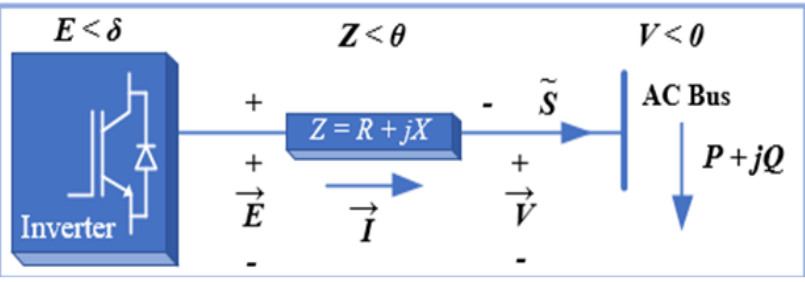

Fig. 10. Diagram of transferred power through a transmission line.

The load active power $\mathrm{P}$ and reactive power $\mathrm{Q}$ can be calculated as [10]:

$$
\left\{\begin{array}{l}
\mathrm{P}=\frac{\mathrm{EVR}}{\mathrm{R}^{2}+\mathrm{x}^{2}} \cos \alpha-\frac{\mathrm{V}^{2} \mathrm{R}}{\mathrm{R}^{2}+\mathrm{x}^{2}}+\frac{\mathrm{EVX}}{\mathrm{R}^{2}+\mathrm{x}^{2}} \sin \alpha \\
\mathrm{Q}=\frac{\mathrm{EVX}}{\mathrm{R}^{2}+\mathrm{x}^{2}} \cos \alpha-\frac{\mathrm{V}^{2} \mathrm{X}}{\mathrm{R}^{2}+\mathrm{x}^{2}}+\frac{\mathrm{EVR}}{\mathrm{R}^{2}+\mathrm{x}^{2}} \sin \alpha
\end{array}\right.
$$

(7) is a nonlinear static equation and needs to be linearized and decoupled at the equilibrium point:

$\left[\begin{array}{l}\mathrm{P} \\ \mathrm{Q}\end{array}\right]=\left[\begin{array}{ll}\frac{\partial \mathrm{P}}{\partial \alpha} & \frac{\partial \mathrm{P}}{\partial \mathrm{E}} \\ \frac{\partial \mathrm{Q}}{\partial \alpha} & \frac{\partial \mathrm{Q}}{\partial \mathrm{E}}\end{array}\right]\left[\begin{array}{c}\Delta \alpha \\ \Delta \mathrm{E}\end{array}\right]$

$E=\sqrt{\left(V+\frac{P R+Q X}{V}\right)^{2}+\left(\frac{P X-Q R}{V}\right)^{2}}$

$\alpha=\arctan \frac{\mathrm{PX}-\mathrm{QR}}{\mathrm{V}^{2}+\mathrm{PR}+\mathrm{QX}}$

The elements of the coefficient matrix of Eqn. 8 are given by:

$$
\begin{aligned}
& \frac{\partial \mathrm{P}}{\partial \alpha}=\frac{1}{\mathrm{R}^{2}+\mathrm{X}^{2}}\left(-\mathrm{E}_{0} \mathrm{VR} \sin \alpha_{0}+\mathrm{E}_{0} \mathrm{VX} \cos \alpha_{0}\right) \\
& \frac{\partial \mathrm{P}}{\partial \mathrm{E}}=\frac{1}{\mathrm{R}^{2}+\mathrm{X}^{2}}\left(\mathrm{VR} \cos \alpha_{0}+\mathrm{VX} \sin \alpha_{0}\right) \\
& \frac{\partial \mathrm{Q}}{\partial \alpha}=\frac{1}{\mathrm{R}^{2}+\mathrm{X}^{2}}\left(-\mathrm{E}_{0} \mathrm{VX} \sin \alpha_{0}-\mathrm{E}_{0} \mathrm{VR} \cos \alpha_{0}\right) \\
& \frac{\partial \mathrm{Q}}{\partial \mathrm{E}}=\frac{1}{\mathrm{R}^{2}+\mathrm{X}^{2}}\left(\mathrm{VX} \cos \alpha_{0}-\mathrm{VR} \sin \alpha_{0}\right)
\end{aligned}
$$

The proposed droop control equation is thus obtained as:

$$
\left[\begin{array}{l}
\mathrm{f} \\
\mathrm{E}
\end{array}\right]=\left[\begin{array}{c}
\mathrm{f}^{*} \\
\mathrm{E}^{*}
\end{array}\right]+\left[\begin{array}{cc}
\frac{2 \delta_{\mathrm{f}}}{\pi} & -\frac{2 \delta_{\mathrm{f}}}{\pi} \\
\frac{2 \delta_{\mathrm{E}}}{\pi} & \frac{2 \delta_{\mathrm{E}}}{\pi}
\end{array}\right]\left[\begin{array}{l}
\left(\arctan \left(\mu_{\mathrm{p}}\left(\mathrm{P}^{*}-\mathrm{P}\right)\right)\right) \\
\left(\arctan \left(\mu_{\mathrm{q}}\left(\mathrm{Q}^{*}-\mathrm{Q}\right)\right)\right)
\end{array}\right](10)
$$

where $\mathrm{P}, \mathrm{Q}, \mathrm{P}^{*}$, and $\mathrm{Q}^{*}$ are the instantaneous active power, instantaneous reactive power, reference active power, reference reactive power respectively. The rated frequency is written as $\mathrm{f}^{*}$, and ${ }^{\wedge} *$ is the rate voltage. $\delta \_f$ and $\delta \_E$ are the multiplier coefficients of arctan function that determine the limit value of variation of frequency and voltage respectively. $\mu \_p$ and $\mu \_q$ are the concavity coefficients of trigonometric function that determine the limit value of variation of active power and reactive power, respectively.

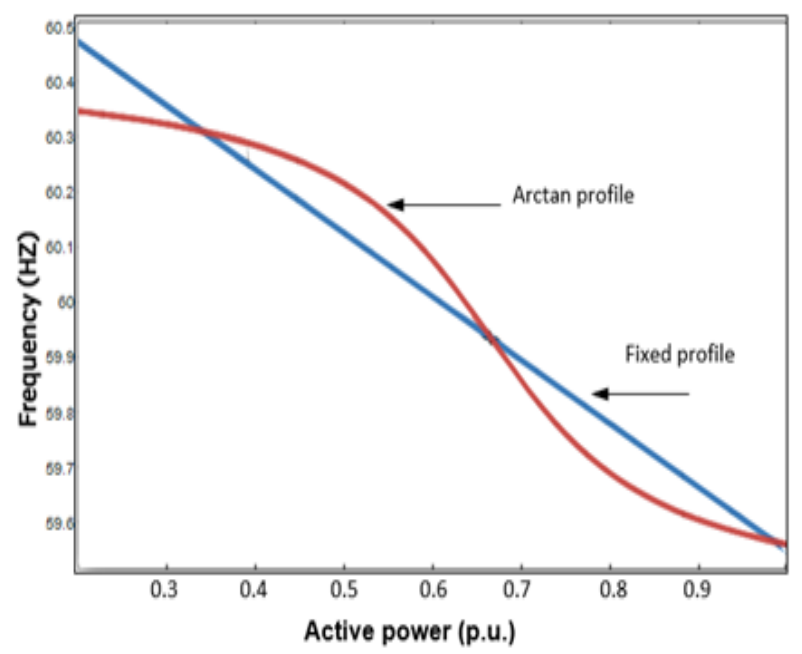

Fig. 11. Comparison between the traditional droop profile and arctan profile.

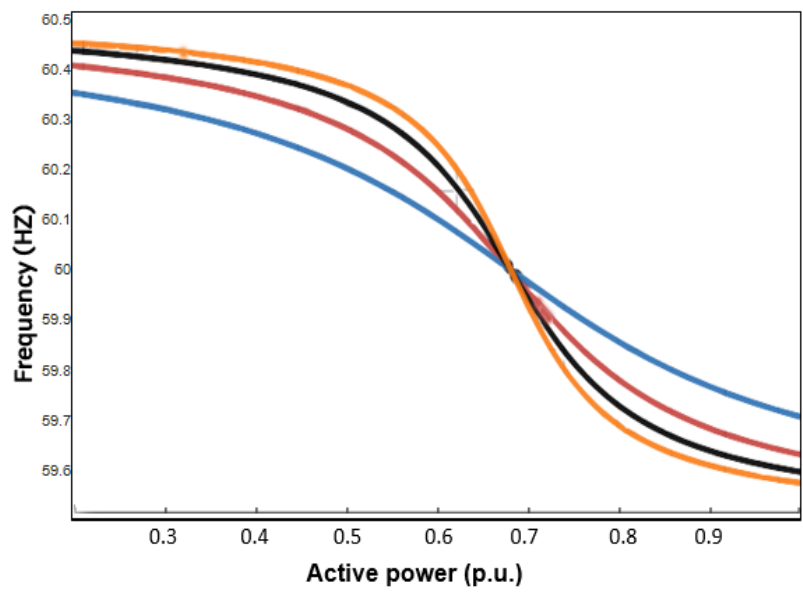

Fig. 12. Different arctan functions with different values of concavity coefficients $\mu$. 


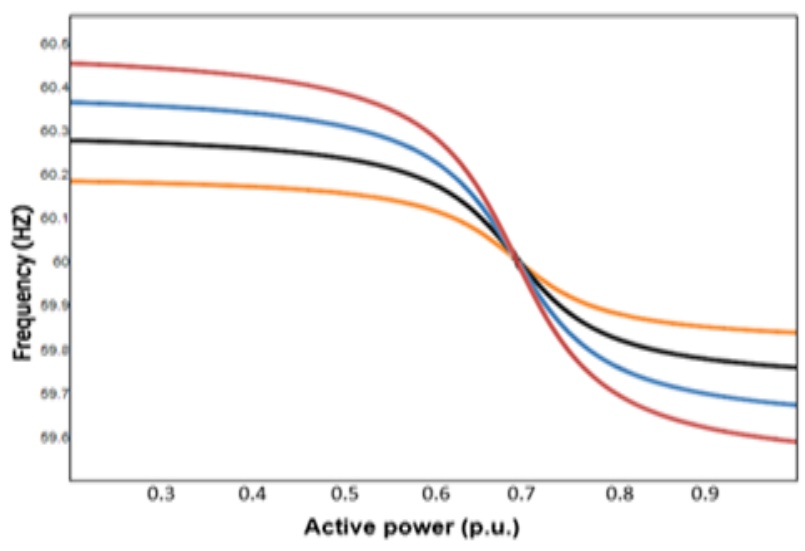

Fig. 13. Different arctan functions with different values of concavity coefficients $\mu$.

Fig. 11 shows a comparison between the traditional droop profile and arctan profile. where the arctan profile have a nonlinearity that allow a larger ability to fast response. Fig. 12 and Fig. 14 shows different arctan functions with different values of multiplier $\delta$ and concavity coefficients $\mu$. Fig. 12 . shows the active power and reactive power is calculated from the inverter output. Then the active power is compared with the active power reference and then multiplied by the arctan function. The outcome will add the coupled part that comes from reactive power. The exact process is performed for the reactive power, but from the result, the sine wave will be generated and controlled by the inner loop controller. The pulse width modulator converts the output of the internal loop controller to the necessary pulses of the gate.

\section{FUZZY LOGIC BASED LOAD FREQUENCY CONTROL}

Fuzzy logic enables system control through a decisionmaking process without the need for conventional crisp mathematical system model [29]. Fuzzy logic technique can overcome the influence of the system nonlinear factors thereby enabling the utilization of a curved line in place of the straight line frequency droop characteristics for the ALFC control of island microgrids. This method thus minimizes the problem of frequency crossing. The problem that happens when frequency deviates from the specified value and does not return to the same value after a large disturbance is referred to as frequency crossing. In the fuzzy integrated ALFC, the PI controller gains $\mathrm{Kp}$ and $\mathrm{Ki}$ are tuned with reference to the feedback of the frequency deviation from the specified value

The input and output variables of the proposed fuzzy logic ALFC controller are represented as a set of seven-linguistic variables as NB - Negative Big, NM - Negative Medium, NS - Negative Small, ZO - Zero, PS - Positive Small, PM Positive Medium and PB - Positive Big.

Proposed fuzzy logic controller have two inputs and two outputs. first input is the frequency error between the instantaneous frequency value and the reference value. Second input is the derivative of this error value. According to the value of the error and the derivative of this error [29], fuzzy rules are generated to tune the two output variables: the proportional gain $(K p)$ and the integral gain $(K \mathrm{i})$ respectively.

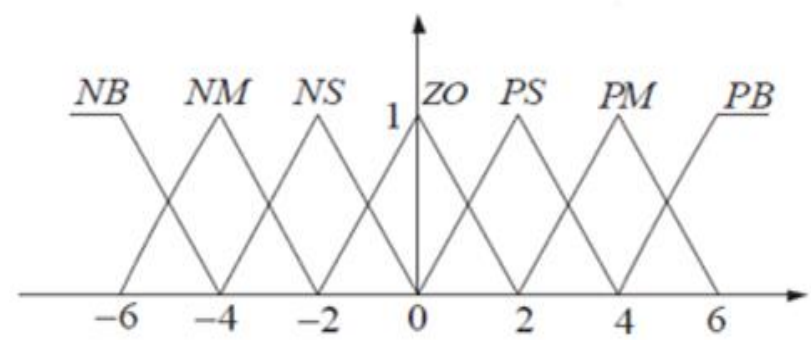

Fig. 15. Triangular fuzzy subsets for the error and rate of change in error. TABLE I: THE ARRANGEMENT OF CHANNELS

TABLE I. THE FUZZY RULE TABLE OF KI

\begin{tabular}{cccccccc}
\hline Ec & \multicolumn{7}{c}{ e } \\
\hline & NB & NM & NS & ZO & PS & PM & PB \\
NB & PB & PB & PM & PM & PS & ZO & ZO \\
NM & PB & PB & PM & PM & PS & ZO & ZO \\
NS & PM & PM & PM & PS & ZO & NS & NS \\
ZO & PM & PM & PS & ZO & NS & NM & NM \\
PS & PS & PS & ZO & NS & NS & NM & NM \\
PM & ZO & ZO & NS & NM & NM & NB & NB \\
PB & ZO & ZO & NS & NM & NM & NB & NB \\
\hline
\end{tabular}

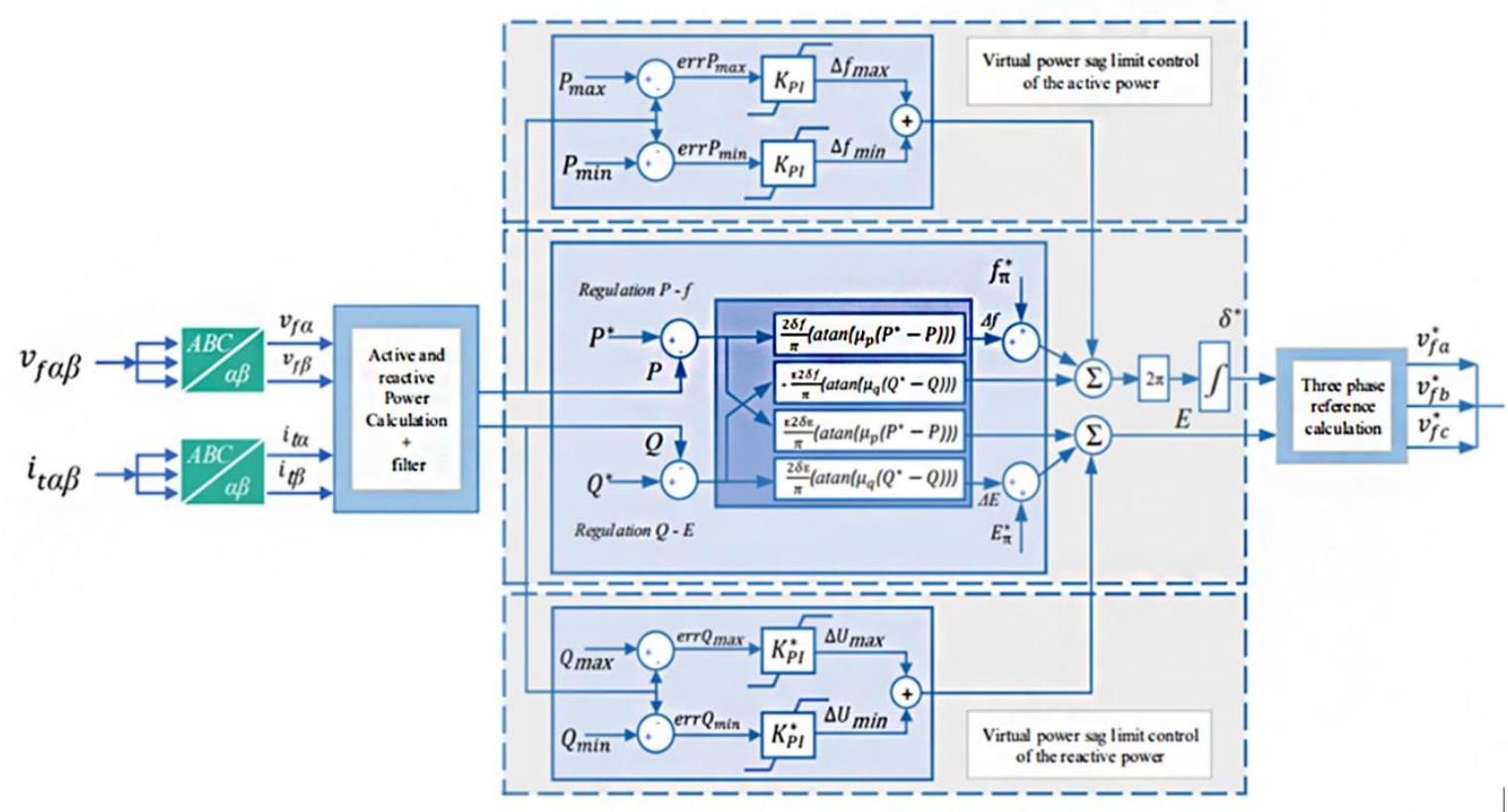

Fig. 14. Decoupled Trigonometric Saturated droop control. 
TABLE II. THE FUZZY RULE TABLE OF KP

\begin{tabular}{ccllllll}
\hline & & & & e & & \\
\hline ec & NB & NM & NS & ZO & PS & PM & PM \\
NB & NB & NB & NB & NB & NM & NS & ZO \\
NM & NB & NB & NB & PM & NS & ZO & PS \\
NS & NB & NB & NM & NS & ZO & PS & PM \\
ZO & NB & NM & NS & ZO & PS & PM & PB \\
PS & NM & NS & ZO & PS & PM & PB & PB \\
PM & NS & ZO & PS & PM & PB & PB & PB \\
\hline
\end{tabular}

The two instantaneously sampled crisp values obtained as input are mapped into linguistic values which are then combined by using "sum" method in which the fuzzy control rules of "if e and ec then $\mathrm{Kp}$ and if e and ec then $\mathrm{Ki}$ " are adopted. Finally, the "centroid" method is used for defuzzification, for converting the output to a crisp value. Fig. 17 shows the block diagram of the fuzzy logic based droop control for ALFC.

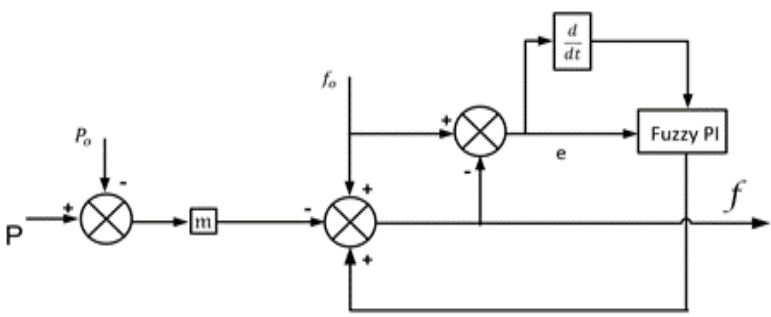

Fig. 17. Block diagram of Fuzzy droop control.

The Fuzzy logic droop control equation inserted into the PI regulator can be expressed as:

$$
f=f_{0}-m_{i} P_{i}+\left(k_{p}+\frac{k_{i}}{s}\right)\left(f_{0}-f\right)
$$

where $\mathrm{f}$ is the instantaneous frequency, $\mathrm{m} \_\mathrm{i}$ is the droop officiant, $\mathrm{P}_{-} \mathrm{i}$ the active power, $\mathrm{i}$ in " $\mathrm{m} \mathrm{i}_{\mathrm{i}} \mathrm{i}$ " is the droop coefficient, and k_p,k_(i )are the proportional and integral gain settings respectively.

Due to the role of frequency recovery control, its expression is as follows:

$$
\begin{gathered}
f=f_{0}-m\left(P-P_{0}\right), P_{0} \leq P \leq P_{1} \\
f=f_{0}-\left[m-m_{1}\left(P-P_{1}\right)\right]\left(P-P_{1}\right), P_{1} \leq P \leq P_{\max }
\end{gathered}
$$

When the instantons active power measured between $\mathrm{P} 0$ and $\mathrm{P} 1$, the droop coefficient adjustment follows the linear droop characteristic just like conventional droop controller. but when the load is cut at a large load and the instantons power measured between P1 and Pmax, the proposed method can adaptively change the droop coefficient, and effectively prevent the frequency from crossing the boundary compared with the conventional droop characteristic and destabilizes the system. The active droop curve when $\mathrm{m} 1$ takes different values is shown in Fig. 18. In order to ensure that the system has certain droop characteristics in the operating range, $\mathrm{m}$ $\mathrm{m} 1(\mathrm{P}-\mathrm{P} 1)>0$ must be satisfied, so $\mathrm{m} 1$ is between $0.3 \mathrm{~m} / \mathrm{P} 1$ and $0.6 \mathrm{~m} / \mathrm{P} 1$. In order to better suppress the drop of the frequency, $0.6 \mathrm{~m} / \mathrm{P} 1$ is selected as the value of $\mathrm{m} 1$.

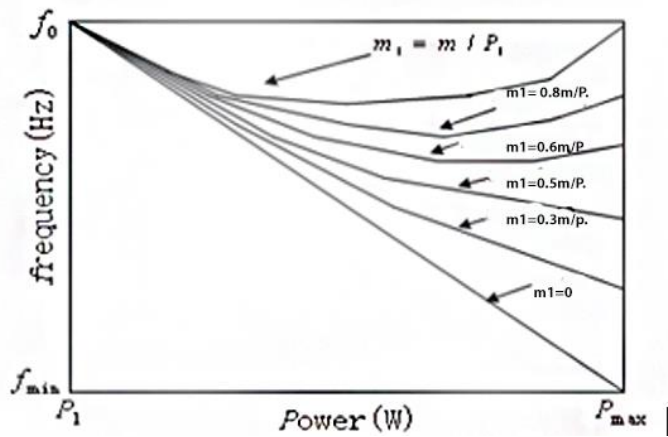

Fig. 18. Droop curves with different value of $\mathrm{m} 1$.

\section{SySTEM DATA AND SimULATION RESULTS}

To evaluate the effectiveness of the conventional droop ALFC controller, the DTS based ALFC controller, and the fuzzy logic based ALFC controller, the microgrid with four distributed generators shown in Fig. 19, operating in the isolated mode is utilized. The microgrid system data and the controller parameters are given in Table III. The simulations are performed in the MATLAB/SIMULINK environment. The simulations of present case studies are achieved by using MATLAB version R2019b and RT-EVENTS toolbox from OPAL-RT to model the inverter.

It is assumed that all the inverters have the same capacity. In During the period from $0 \sim 1.5$ seconds, there are two loads with a total of $14 \mathrm{~kW}$ demand in the system. At 1.5 seconds, load number 2 with $4 \mathrm{~kW}$ is switched off to initiating a disturbance in the system. After $1.75 \mathrm{~s}$, the load number 2 is reconnected back into the system. The frequency variations of the four distributed generators for different controller are shown in Fig. 20 to Fig. 31., respectively.

\begin{tabular}{cc}
\multicolumn{2}{c}{ TABLE III: THE FUZZY RULE TABLE OF KP } \\
\hline \multicolumn{2}{c}{ MicroGrid Data } \\
\hline Apparent Power (VA) & $\mathrm{S}=20 \mathrm{e} 3$ \\
Nominal MicroGrid voltage RMS value & $\mathrm{v}=208$ \\
(VrmsLL) (V) & $\mathrm{Vdc}=500$ \\
Nominal DC-link voltage (V); & $\mathrm{F}=60$ \\
MicroGrid Frequency (Hz) & $\mathrm{fs}=2000$ \\
PWM Switching Frequency (HZ) & 10,4 \\
Load 1 and 2 (kW) &
\end{tabular}

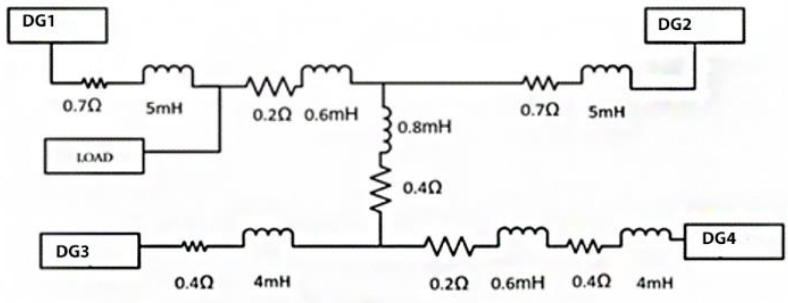

Fig. 19. Meshed microgrid structure.

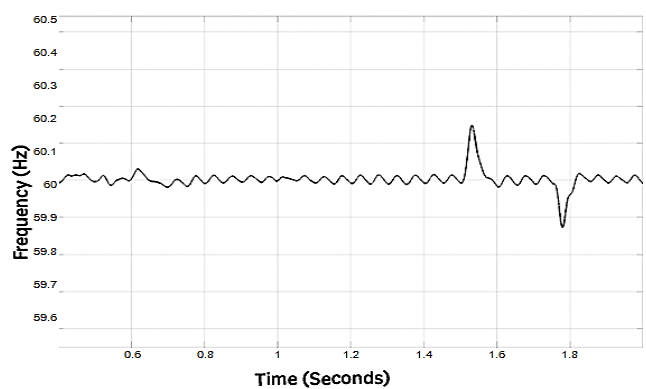

Fig. 20. The frequency of Conventional droop controller at DG1. 


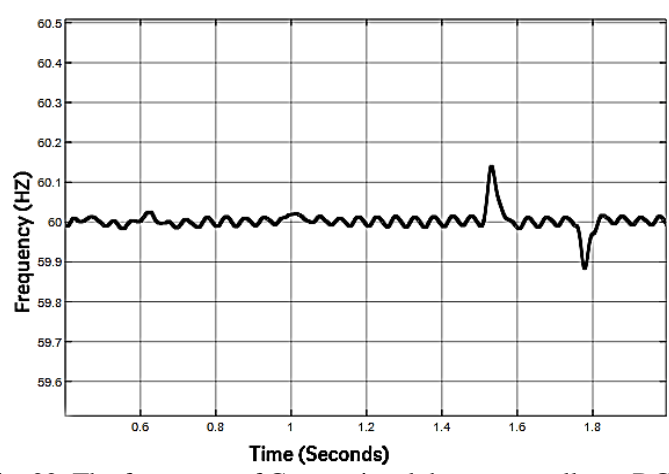

Fig. 22. The frequency of Conventional droop controller at DG3.

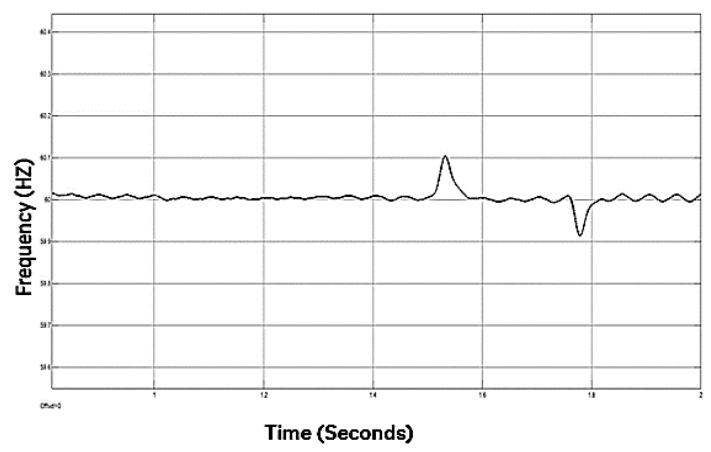

Fig. 24. The frequency of DTS controller at DG1.

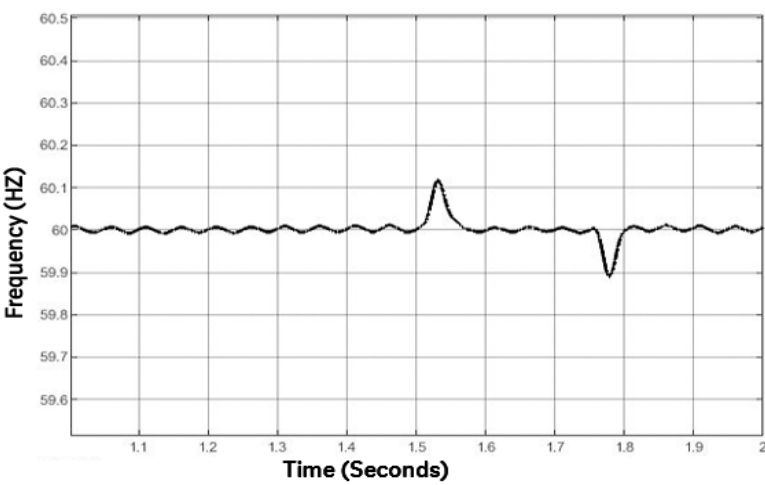

Fig. 26. The frequency of DTS controller at DG3.

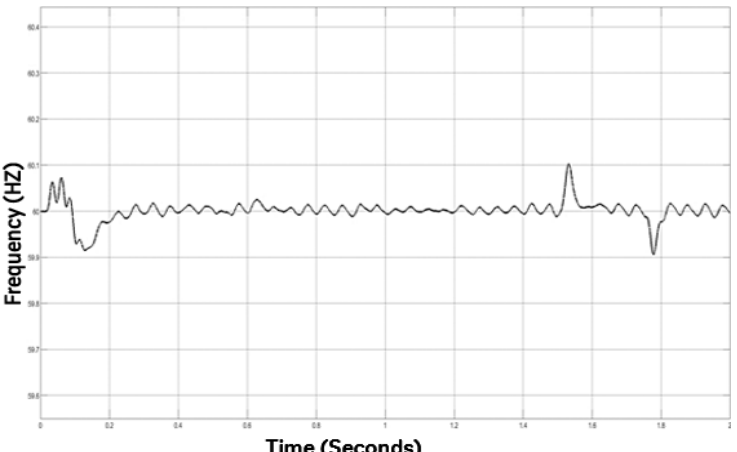

Fig. 28. The frequency of Fuzzy logic controller at DG1.

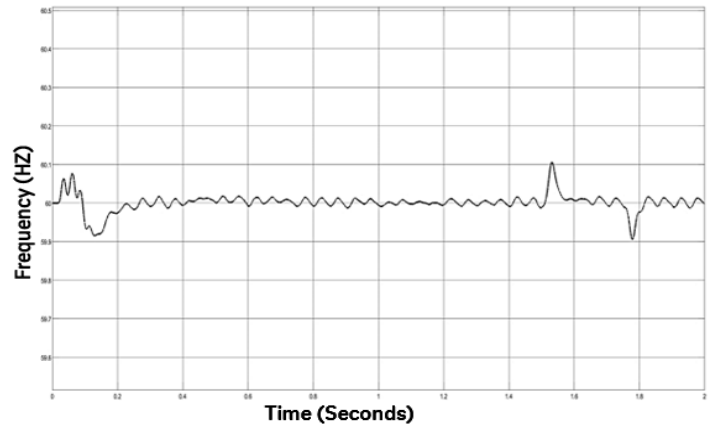

Fig. 30. The frequency of Fuzzy logic controller at DG3.

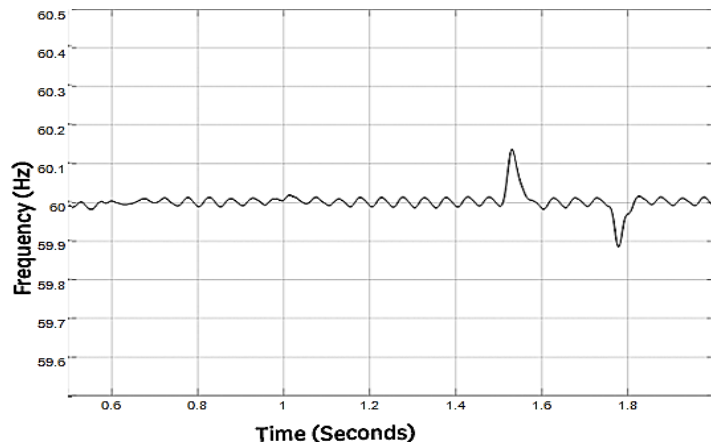

Fig. 21. The frequency of Conventional droop controller at DG2.

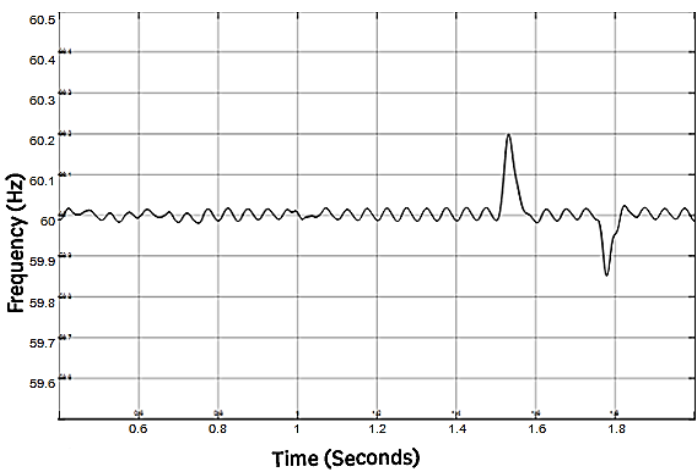

Fig. 23. The frequency of Conventional droop controller at DG4.

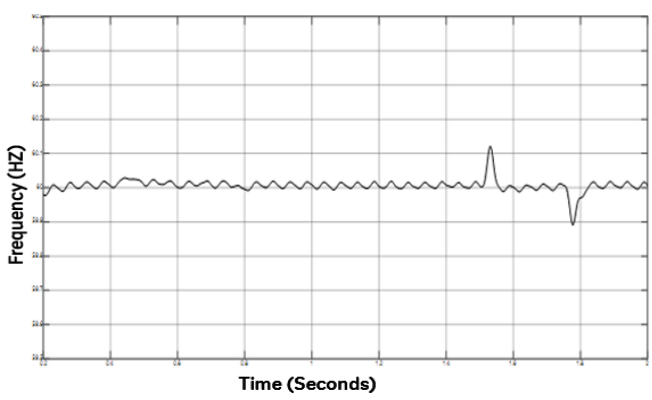

Fig.25. The frequency of DTS controller at DG2.

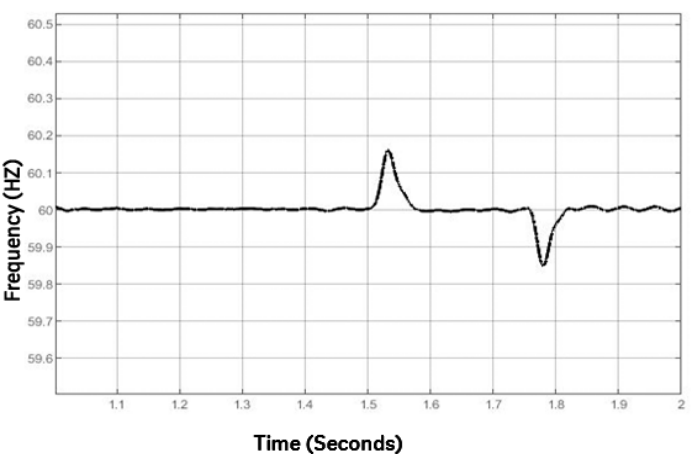

Fig. 27. The frequency of DTS controller at DG4.

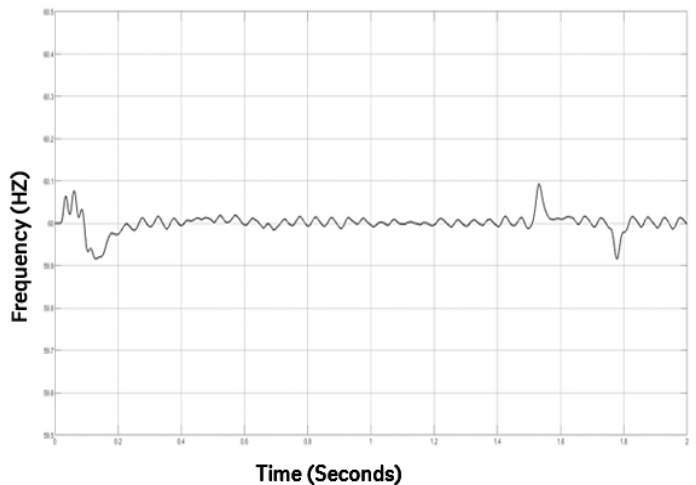

Fig. 29. The frequency of Fuzzy logic controller at DG2. 


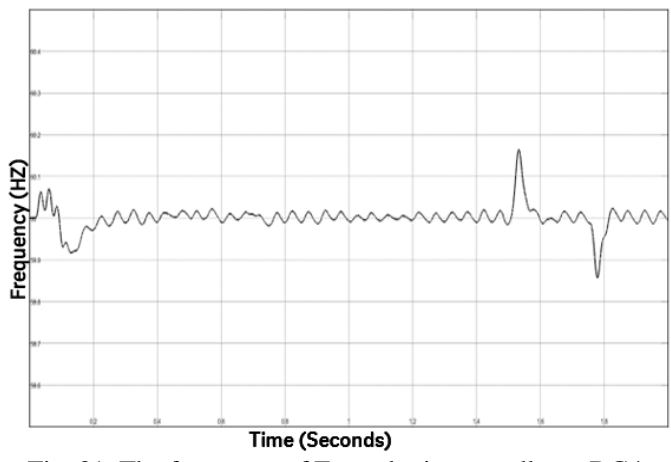

Fig. 31. The frequency of Fuzzy logic controller at DG4

From Table IV it can be seen that, with the proposed DTS controller at DG1, following the load disturbances connecting load $2(4 \mathrm{~kW})$, the frequency deviates up to $60.10 \mathrm{~Hz}$ and then back to the average value of $60 \mathrm{~Hz}$ within 83 milliseconds. On the other hand, the conventional droop controller takes 156 milliseconds. Similarly, at $t=1.75$ seconds, when load 2 with $4 \mathrm{~kW}$ is connected back to the common bus, with the proposed DTS controller at DG1, the frequency falls to $59.92 \mathrm{~Hz}$. However, with the conventional droop controller, the frequency drops to $59.87 \mathrm{~Hz}$. DG2, DG3, and DG4 also show a similar response as obtained for DG1 with the droop and DTS controllers. The reduction in the percentage settling time of DG4 following the load disturbance is $53.2 \%$. This value is maximum among all DG's when the DTS technique is utilized instead of droop frequency control technique.

Thus it can be inferred that the DTS controller is capable of providing better steady-state and transient performance when compared with a conventional droop frequency controller. The fuzzy rule table of Kp.

From Table V. it can be seen that the Fuzzy logic controller at DG 1 following the load disturbance of disconnecting load $2(4 \mathrm{~kW})$, the frequency deviates up to $60.10 \mathrm{~Hz}$ then returns o the average value of $60 \mathrm{~Hz}$ within 88 milliseconds. On the other hand, the DTS controller takes 83 milliseconds. Similarly, At $\mathrm{t}=1.75 \mathrm{~s}$, Load 2 with 4 kilos, at $\mathrm{t}=1.75$ seconds, when load 2 with $4 \mathrm{~kW}$ is connected back to the common bus, with the proposed Fuzzy logic controller at DG1, the frequency falls to $59.91 \mathrm{~Hz}$ while with the DTS controller, the frequency falls to $59.92 \mathrm{~Hz}$. DG2, DG3, and DG4 also show a similar response as obtained for DG1 with the Fuzzy and DTS controllers.

Thus, the Fuzzy logic controller shows a similar response as obtained from the DTS controller.

\section{CONCLUSION}

This paper has dealt with the new techniques for the automatic load frequency control of islanded microgrids meshed structure. Microgrids are established as a part of the smart grid environment. The main objective is to develop the effectiveness of these techniques compared to the conventional PI load-frequency control of islanded microgrids.

According to the droop line technique, a conventional droop controller was used to control the frequency and share the active power by changing their frequency. We observed the frequency deviation when the load suddenly changes by connected or disconnecting a part of the load. We explained the relation between active power, frequency sharing, and conventional droop control.

We replaced the droop line with the arctan function in the decoupled trigonometric saturated droop control to enhance the active power-sharing and transient response. In the DTS controller, we coupled the active power with voltage according to the traditional relationship between active power and frequency. Thus, results in coupling the relation between the reactive power and frequency according to the conventional relationship between reactive power and voltage. Then we compare the Decoupled trigonometric saturated droop control with the traditional controller of droop.

In the fuzzy integrated ALFC, the PI controller gains $\mathrm{Kp}$, and $\mathrm{Ki}$ is tuned regarding the frequency deviation feedback from the specified value. Afterward, we compare the Fuzzy logic controller result with the Decoupled trigonometric saturated droop control.

In total, this thesis is an investigation of new techniques for the automatic load frequency control of islanded microgrids for Conventional Droop control, decoupled trigonometric saturated droop controller, and Fuzzy logic controller. We showed that the DTS controller and Fuzzy logic controller succeeded in decreasing the short response time concerning conventional droop control.

TABLE IV: THE MAXIMUM AND MinimUM VALUES OF THE FREQUENCY OF VARIOUS DGS FOR FUZZY LOGIC CONTROLLER

\begin{tabular}{ccccccc}
\hline & \multicolumn{2}{c}{ Conventional droop controller } & \multicolumn{3}{c}{ DTS controller } \\
\cline { 2 - 7 } & $\begin{array}{c}\text { Maximum } \\
(\mathrm{Hz})\end{array}$ & $\begin{array}{c}\text { Minimum } \\
(\mathrm{Hz})\end{array}$ & $\begin{array}{c}\text { R. time } \\
(\mathrm{mS})\end{array}$ & $\begin{array}{c}\text { Maximum } \\
(\mathrm{Hz})\end{array}$ & $\begin{array}{c}\text { Minimu } \\
\mathrm{m}(\mathrm{Hz})\end{array}$ & $\begin{array}{c}\text { Response } \\
\text { time } \\
(\mathrm{mS})\end{array}$ \\
\hline DG1 & 60.14 & 59.87 & 156 & 60.10 & 50.92 & 83 \\
DG2 & 60.14 & 59.88 & 158 & 60.12 & 50.90 & 84 \\
DG3 & 60.15 & 59.88 & 158 & 60.12 & 50.90 & 84 \\
DG4 & 60.20 & 59.84 & 166 & 60.16 & 50.86 & 87 \\
\hline
\end{tabular}

TABLE V. The MAXIMUM AND Minimum VALUeS OF THE FREQUENCY OF VARIOUS DGS FOR FUZZy LoGic CONTROLLER

\begin{tabular}{lcccccc}
\hline & \multicolumn{2}{c}{ Conventional droop controller } & \multicolumn{3}{c}{ DTS controller } \\
\cline { 2 - 7 } & $\begin{array}{c}\text { Maximum } \\
(\mathrm{Hz})\end{array}$ & $\begin{array}{c}\text { Minimum } \\
(\mathrm{Hz})\end{array}$ & $\begin{array}{c}\mathrm{R} . \\
\text { time } \\
(\mathrm{mS})\end{array}$ & $\begin{array}{c}\text { Maximum } \\
(\mathrm{Hz})\end{array}$ & $\begin{array}{c}\text { Minimum } \\
(\mathrm{Hz})\end{array}$ & $\begin{array}{c}\text { Response } \\
\text { time }(\mathrm{mS})\end{array}$ \\
\hline DG1 & 60.10 & 50.92 & 83 & 60.10 & 59.91 & 88 \\
DG2 & 60.12 & 50.90 & 84 & 60.09 & 59.92 & 89 \\
DG3 & 60.12 & 50.90 & 84 & 60.11 & 59.91 & 89 \\
DG4 & 60.16 & 50.86 & 87 & 60.17 & 59.87 & 92 \\
\hline
\end{tabular}




\section{REFERENCES}

[1] Blaabjerg, Zhe Chen and S. B. Kjaer, "Power electronics as efficient interface in dispersed power generation systems," in IEEE Transactions on Power Electronics, vol. 19, no. 5, pp. 1184-1194, Sept. 2004, doi: 10.1109/TPEL.2004.833453.

[2] T. Markvart, Solar Electricity, 2nd ed. New York: Wiley, 2000.

[3] S. V. Kulkarni and D. N. Gaonkar, "Operation and control of a microgrid in isolated mode with multiple distributed generation systems," 2017 International Conference on Technological Advancements in Power and Energy (TAP Energy), Kollam, 2017, pp. 1-6, doi: 10.1109/TAPENERGY.2017.8397210.

[4] Schwaegerl and L. Tao, "The microgrids concept", Microgrids, pp.124, Dec. 2013.

[5] L. Lin, H. Ma and Z. Bai, "An Improved Proportional Load-Sharing Strategy for Meshed Parallel Inverters System with Complex Impedances," in IEEE Transactions on Power Electronics, vol. 32, no. 9, pp. 7338-7351, Sept. 2017, doi: 10.1109/TPEL.2016.2630709.

[6] Basilio Gentile, Sandro Zampieri, John W. Simpson-Porco, Florian Dörfler and Francesco Bullo, On Reactive Power Flow and Voltage Stability in Microgrids. NSF Grant.

[7] Yasser Rahmati Kukandeh, Hassan Rahmati Kukandeh and Mohammed Hossein Kazemi, Controlling Voltage and Frequency of a Power Network with Microgrid Using Droop Method. Global Journal of Researches in Engineering Electrical And Electronics Engineering, USA, 1st edition, 2011

[8] M. R. Tur and R. Bayindir, "A Review of Active Power and Frequency Control in Smart Grid," 2019 1st Global Power, Energy and Communication Conference (GPECOM), Nevsehir, Turkey, 2019, pp. 483-488.

[9] S. Vadi, S. Padmanaban, R. Bayindir, F. Blaabjerg, L. Mihet-Popa, "A review on optimization and control methods used to provide transient stability in microgrids", Energies, vol. 12, no. 18, pp. 3582, Sep. 2019.

[10] Bouzid, A.E.M.; Sicard, P.; Chaoui, H.; Cheriti, A.; Sechilariu, M.; Guerrero, J. A novel Decoupled Trigonometric Saturated droop controller for power sharing in islanded low-voltage microgrids. Electr. Power Syst. Res. 2019, 168, 146-161, doi:10.1016/j.epsr.2018.11.016

[11] [E. Rokrok, M.E.H. Golshan, Adaptive voltage droop scheme for voltage source converters in an islanded multibus microgrid, IET Gener. Transm. Distrib. 4 (5) (2010) 562-578.

[12] Q. Shafiee, J.C. Vasquez, J.M. Guerrero, Distributed secondary control for islanded Micro Grids a networked control systems approach, IECON 2012 - 38th Annual Conference on IEEE Industrial Electronics Society (2012) 5637-5642.

[13] X. Lu, X. Yu, J. Lai, Y. Wang and J. M. Guerrero, "A Novel Distributed Secondary Coordination Control Approach for Islanded Microgrids," in IEEE Transactions on Smart Grid, vol. 9, no. 4, pp. 2726-2740, July 2018, doi: 10.1109/TSG.2016.2618120.

[14] J. W. Simpson-Porco, Q. Shafiee, F. Dörfler, J. C. Vasquez, J. M. Guerrero and F. Bullo, "Secondary Frequency and Voltage Control of
Islanded Microgrids via Distributed Averaging," in IEEE Transactions on Industrial Electronics, vol. 62, no. 11, pp. 7025-7038, Nov. 2015, doi: 10.1109/TIE.2015.2436879.

[15] Li, D.; Zhao, B.; Wu, Z.; Zhang, X.; Zhang, L. An Improved Droop Control Strategy for Low-Voltage Microgrids Based on Distributed Secondary Power Optimization Control. Energies 2017, 10, 1347.

[16] Li Yanqing, Guo Tong, Yuan Yanwu. Active and frequency control strategy of micro-grid based on improved droop control. Electrical Measurement and Instrumentation, 2017, 54(12):60-64.

[17] Chen Kun, Cao Yilong, Jiang Youhua. Improved droop control strategy in micro-grid parallel Inverter. Power Electronics,2017,51(01):29-32.

[18] Tang Kunming, Wang Junjie, Zhang Taiqin. Research on control strategy for microgrid based on adaptive droop control[J]. Power System Protection and Control, 2016,44(18):68-74.

[19] Z. Sun, S. An, Z. Wei, F. Qiu and K. Zhong, "Active and Frequency Control Strategy of Improved Droop Control in Islanded Micro-grid," 2019 IEEE International Conference on Robotics and Biomimetics (ROBIO), Dali, China, 2019, pp. 2636-2640, doi: 10.1109/ROBIO49542.2019.8961827.

[20] M. Khooban, T. Niknam, M. Shasadeghi, T. Dragicevic and F. Blaabjerg, "Load Frequency Control in Microgrids Based on a Stochastic Noninteger Controller," in IEEE Transactions on Sustainable Energy, vol. 9, no. 2, pp. 853-861, April 2018.

[21] L. Wu, H. Liu, K. Bai and Z. Cui, "A coordinated control strategy of active power and voltage for large scale wind-storage combined generation system," 2016 International Conference on Condition Monitoring and Diagnosis (CMD), Xi'an, 2016, pp. 811-814.

[22] C. Dou, Z. Zhang, D. Yue, M. Song, Improved droop control based on virtual impedance and virtual power source in low-voltage microgrid IET Gener. Transm. Distrib. 11 (4) (2017) 1046-1054.

[23] F. Blaabjerg, Zhe Chen and S. B. Kjaer, "Power electronics as efficient interface in dispersed power generation systems," in IEEE Transactions on Power Electronics, vol. 19, no. 5, pp. 1184-1194, Sept. 2004.

[24] T. Markvart, Solar Electricity, 2nd ed. New York: Wiley, 2000.

[25] Global Wind Energy Council, global wind. GWEC 2017.

[26] Saudi Arabia's Vision for 2030, Saudi Arabia's Vision for 2030 report. SA Gov 2016.

[27] Jiri Lettl, Jan Bauer, and Libor Linhar; "Comparison of Different Filter Types for Grid Connected Inverter", PIERS Proceedings, Marrakesh, MOROCCO, March 20-23, 2011

[28] Z. Sun, S. An, Z. Wei, F. Qiu and K. Zhong, "Active and Frequency Control Strategy of Improved Droop Control in Islanded Micro-grid," 2019 IEEE International Conference on Robotics and Biomimetics (ROBIO), Dali, China, 2019, pp. 2636-2640, doi 10.1109/ROBIO49542.2019.8961827.

[29] Wu Xuemin, Jiang Lin. Simulation of three-phase photovoltaic gridconnected inverter based on fuzzy PI control[J]. Techniques of Automation and Application, 2015,34(9):80-85. 